\title{
Study on Adsorption Capacities of Heavy Metals in Biofilms Grown on Magnetic Carriers
}

\author{
Zhaoxu LI \\ Pearl River Hydraulic Research Institute \\ Pearl River Water Resources Commission \\ Guangzhou, Guangdong, 510611, China \\ e-mail: syslzx@126.com
}

\section{Ran JIANG}

Pearl River Hydraulic Research Institute

Pearl River Water Resources Commission

Guangzhou, Guangdong, 510611, China

e-mail: 458750084@qq.com

\author{
Fang YANG \\ Pearl River Hydraulic Research Institute \\ Pearl River Water Resources Commission \\ Guangzhou, Guangdong, 510611, China \\ e-mail: 532839727@qq.com \\ Liqiang XU \\ Pearl River Hydraulic Research Institute \\ Pearl River Water Resources Commission \\ Guangzhou, Guangdong, 510611, China \\ e-mail: 19245856@qq.com
}

\begin{abstract}
The adsorption capacities of heavy metals in biofilms have the potential advantage of high efficiency. More and more attention has been paid to the study of the adsorption of heavy metals in biofilms. This study designed four reactors to test the adsorption capacities of heavy metals in biofilms grown on three kinds of magnetic carriers and one kind of non-magnetic carriers. The results showed that the heavy metal adsorption capacities of biofilms grown on the magnetic carriers were more than that of biofilms grown on the non-magnetic carriers, and the adsorption capacities of biofilms grown on the magnetic carriers increased with the increasing of the strontium ferrite powder components contained in the carriers and influenced the magnetic field strength. This paper made a beneficial attempt to study on utilizing the magnetic carriers to biologically restore the water polluted by heavy metals.
\end{abstract}

Keywords-heavy metals; adsorption capacity; magnetic carrier; biofilm

\section{INTRODUCTION}

Utilizing the biofilm method to adsorb heavy metals has the potential advantage of high efficiency and low cost, and it gradually aroused people's interest in research [1]. At present, using biofilms method to remediate the contaminated rivers has become a focus in many countries all around the world [2]. When the removal efficiencies for utilizing the biofilm methods to remove $\mathrm{COD}, \mathrm{NH}_{3}-\mathrm{N}, \mathrm{TP}$, and et al., were noticed, the heavy metal adsorption effects of biofilms were also paid more and more attention to in polluted water [3].

A large number of studies have proved that the magnetic field has a promoting effect on the growth of microorganisms and the growth and metabolism of microorganisms will be affected to a certain extent under the action of magnetic field [4]. Moore found that the static magnetic field with uniform intensity $0.3 \mathrm{~T}$ had a stimulating effect on E.coli., and he also found that the oscillating magnetic field had a stimulating effect on the growth of Candida albicans and Pseudomonas aeruginosa and the stimulating effect enhanced with the frequency increasing when the two microorganisms were treated by the oscillating magnetic field with a pulse frequency of $0.1 \sim 0.3 \mathrm{~Hz}$, respectively in his study [5]. Zhang reported that the liquid environment under the action of magnetic field promoted the absorption and excretion of the microorganisms and improved the organisms to absorb enzyme decomposition products [6]. Ji et al. discovered that the magnetic field changed the growth curve of microorganisms and made microbe enter the logarithmic growth phase more quickly after he investigated the influence of magnetic field for activated sludge to process COD in river sewage [7].

In this study, four kinds of magnetic carriers and one kind of non-magnetic carriers were used to test the adsorption capacities of heavy metals in biofilms in the laboratory. The basic data and theories of the heavy metals adsorption capacities of biofilms grown on the magnetic carriers were studied and accumulated. This study had the worthy of being referenced for the heavy metal pollution control in the water polluted by heavy metals.

\section{MATERIALS AND METHODS}

\section{A. Cultivation System Set-up and Operation}

In this study, four identical biological reactors named D1, D2, D3 and D4 were designed to test the adsorption capacity of heavy metals in biofilms grown on magnetic carriers (Figure 1a). For each culture reactor, a container made from glass with the external dimension of $1200 \mathrm{~mm} \times 650 \mathrm{~mm} \times$ $400 \mathrm{~mm}$ (Figure 1b) were separated into 5 flow passages by 4 pieces of glass. There were 5 flow passages sequentially connected through 5 flowing water holes, which were arranged vertically across the interlaced edges of the four glass partitions in the glass container, was served as a water channel. A water pump was fixed for pumping culture medium from a feed tank into the reactor container through a water inlet and a water outlet at the opposite side of the water 
inlet was designed for the culture medium to overflow back into the feed tank.

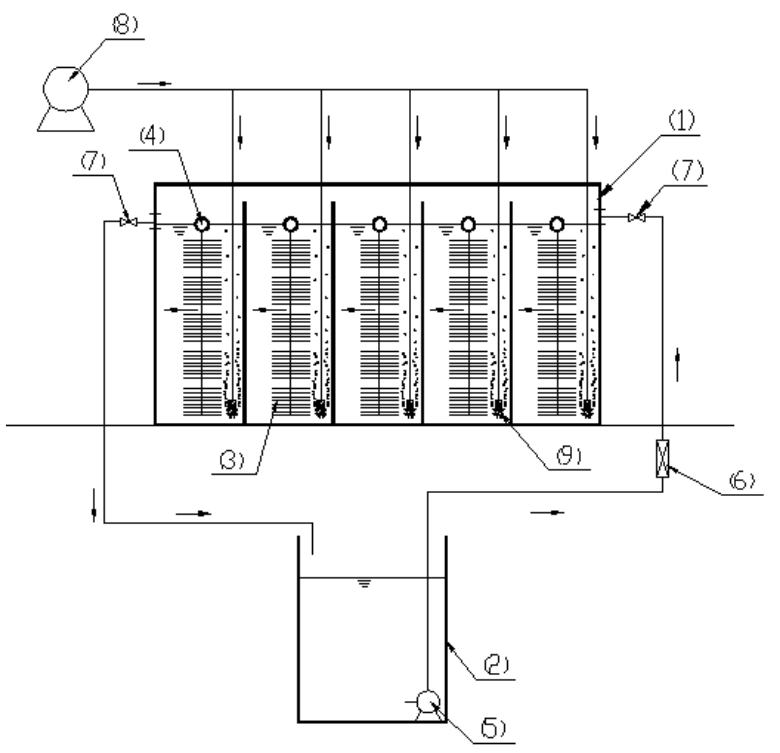

(a)

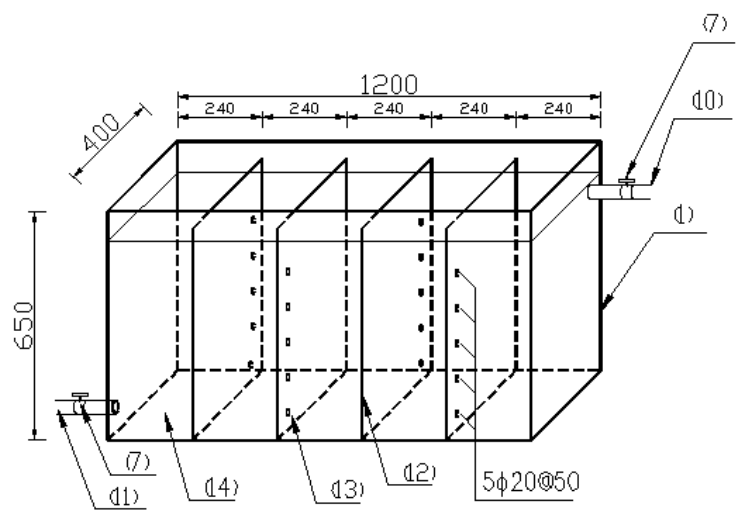

(b)

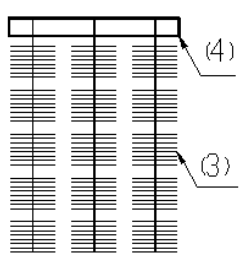

(c)

Figure 1. Schematic diagram of experiment devices: (a) Biological reactor diagram; (b) Elevation drawing of Square container made from glass; (c) Buoy tied three bunches of carriers; (1) container made from glass; (2) feed tank; (3)three-dimensional carriers; (4) cylindrical buoy; (5) water pump; (6)flow meter; (7) water switch; (8) air pump; (9) cylindrical aeration head; (10) water inlet; (11) water outlet; (12) glass partition; (13) flowing water hole; (14) flow passage; Length unit: $\mathrm{mm}$.

For each biological reactor, a $5 \mathrm{~cm}$ thick surface sediment collected from Yayao River was put at the bottom of the container. A large number of in situ microorganisms were contained in the sediments and provided the inoculated microorganisms after the carriers were put into the container to culture biofilms.

In order to maintain a certain amount of DO in the culture medium, an air pump was fixed to supply air directly to each water passage.

The flow rates of the culture medium in the four reactors were all identical and set at $0.3 \mathrm{~m}^{3} /\left(\mathrm{m}^{2} \cdot \mathrm{s}\right)$. The culture medium was uninterruptedly pumped into reactor containers from the feed tank and then flowed back into the feed tank again through the water outlet of the reactor. The culture medium contained nutrients including analytical reagents (AR, Guangzhou Chemical Reagent Factory) as following (all in mg/L): 17.7 of $\left(\mathrm{NH}_{4}\right)_{2} \mathrm{SO}_{4} ; 4.60$ of $\mathrm{Na}_{3} \mathrm{PO}_{4} \cdot 12 \mathrm{H}_{2} \mathrm{O}$; 1.89 of $\mathrm{NaH}_{2} \mathrm{PO}_{4} \cdot 2 \mathrm{H}_{2} \mathrm{O} ; 2.54$ of $\mathrm{NaCl} ; 1.91$ of $\mathrm{KCl} ; 2.05$ of $\mathrm{MgSO}_{4} \cdot 7 \mathrm{H}_{2} \mathrm{O}$; and 0.74 of $\mathrm{CaCl}_{2} \cdot 2 \mathrm{H}_{2} \mathrm{O}$. In order to accelerate biofilm's growth, glucose (Guangzhou Chemical Reagent Factory, Guangzhou, China) was added in the culture medium to maintain the chemical oxygen demand (COD) concentration at about $120 \mathrm{mg} / \mathrm{L}$.

In this study, 4 types of three-dimensional elastic carriers which components showed in Table I were used as the culture substrata of biofilms. The 4 types of carriers included3 types of magnetic carriers (MC01, MC02 and $\mathrm{MC03}$ ) and one type of non-magnetic carrier (nMC) were put into the four biological reactors D1, D2, D3 and D4, respectively. The carriers were made by Aoqun Filter manufacturer (Guangzhou, China). Each carrier having a length of $10 \mathrm{~cm}$ and a diameter of $10 \mathrm{~cm}$ is composed of hundreds of $0.4 \mathrm{~mm}$-diameter polyethylene terephthalate (PET) fiber which were clamped by thin twisting stainless wire. After being pre-weighed, five carriers were stringed together and assembled into a bunch. Three bunches of carriers were tied onto a polyvinyl chloride (PVC) cylindrical buoy with a length of $35 \mathrm{~cm}$ and then they were put into one water passages of the corresponding containers. These bunches of carriers floated in the water in every water passages with the aid of the buoy (Figure 1c). Before the magnetic carriers were assembled, they must be magnetized by use of a magnetizing machine. The magnetic field strength determined by using a handheld tesla meter (Huazhi Instruments and Apparatuses Limited company, Guangzhou) was shown in Table I.

TABLE I. FOUR TYPES OF CARRIERS USED IN THIS STUDY

\begin{tabular}{|c|c|c|c|c|c|c|}
\hline \multirow[b]{2}{*}{ Reactors } & \multirow[b]{2}{*}{ Carrier } & \multicolumn{4}{|c|}{$\begin{array}{c}\text { Percentages of carrier } \\
\text { components }(\%)\end{array}$} & \multirow[b]{2}{*}{$\begin{array}{l}\text { Magnetic field } \\
\text { strength (mT) }\end{array}$} \\
\hline & & PET & $\begin{array}{c}\text { Strontiun } \\
\text { ferrite } \\
\text { powder }\end{array}$ & Dispersant & Others & \\
\hline D1 & MC01 & 88 & 5 & 2 & 5 & 0.15 \\
\hline D2 & MC02 & 83 & 10 & 2 & 5 & 0.30 \\
\hline D3 & MC03 & 78 & 15 & 2 & 5 & 0.40 \\
\hline D4 & $\mathrm{nMC}$ & 93 & 0 & 2 & 5 & 0.00 \\
\hline
\end{tabular}

In this study, six heavy metals including $\mathrm{Cu}, \mathrm{Pb}, \mathrm{Zn}, \mathrm{Cd}$, $\mathrm{Mn}$ and $\mathrm{Ni}$ were selected to test the heavy metal adsorption capacity of the biofilms grown on the magnetic carriers. The concentrations of the six heavy metals in the culture medium of the four reactors were referred to the literature data 
detected to the tidal rivers in South China and shown in Table II $[8,9]$.

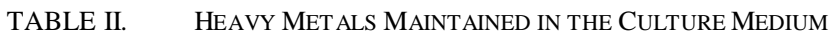

\begin{tabular}{lllllll}
\hline \multirow{2}{*}{ Items } & \multicolumn{6}{l}{ Heavy metals selected for adsorption experiment } \\
\cline { 2 - 7 } & $\mathrm{Cu}$ & $\mathrm{Pb}$ & $\mathrm{Zn}$ & $\mathrm{Cd}$ & $\mathrm{Mn}$ & $\mathrm{Ni}$ \\
\hline $\begin{array}{l}\text { Soluble salts } \\
\text { selected }\end{array}$ & $\mathrm{CuSO}_{4}$ & $\mathrm{PbCl}_{2}$ & $\mathrm{ZnSO}_{4}$ & $\mathrm{CdCl}_{2}$ & $\mathrm{MnSO}_{4}$ & $\mathrm{NiSO}_{4}$ \\
$\begin{array}{l}\text { Concentrations } \\
\text { maintained in }\end{array}$ & & & & & & \\
$\begin{array}{l}\text { Reactors } \\
\text { (mg/L) }\end{array}$ & $\sim 1.00$ & $\sim 0.05$ & $\sim 3.50$ & $\sim 0.05$ & $\sim 1.80$ & $\sim 1.50$ \\
\hline
\end{tabular}

The DO in the culture medium was controlled at approximately $4.0 \mathrm{mg} / \mathrm{L}$ by aeration for about $10 \mathrm{~min}$. every $0.5 \mathrm{~h}$, through a time switch (Hongjinda Electronics Technology Co. Ltd., Guangzhou, China). During the experiment, the $\mathrm{pH}$ was maintained between 6 and 8 with additions of hydrochloric acid(1 M) and sodium hydroxide (1M). The two parameters, DO and $\mathrm{pH}$, were monitored simultaneously using a SC100e Universal Controller (Hach Company, USA). In order to ensure the normal life of microorganisms, approximately $40 \%$ culture medium in the reactor was replaced with the fresh one through the feed tank in every two days. The replaced fresh culture medium contained the six kinds of heavy metals which corresponding concentrations were shown in Table II.

The heavy metals adsorption experiment was run at room temperature of about $28^{\circ} \mathrm{C}$. The temperature in the reactors was also measured with the range of $24 \sim 26^{\circ} \mathrm{C}$. The duration of experiment was about 2 month from August 20 to October 20 in 2015.

\section{B. Sampling Method}

On the 30th day of the experiment, i.e. on the September 20,2015 , two carriers in every one passage were carefully taken out from one reactor. After cutting off the connecting string, one by one of the ten carriers was suspended in 1000 $\mathrm{mL}$ phosphate buffered saline (PBS, pH 7.2), which contained $0.036 \mathrm{~g} \cdot \mathrm{L}^{-1} \mathrm{~K}_{2} \mathrm{HPO}_{4}, 0.092 \mathrm{~g} \cdot \mathrm{L}^{-1} \mathrm{KH}_{2} \mathrm{PO}_{4}$ and $0.493 \mathrm{~g} \cdot \mathrm{L}^{-1} \mathrm{NaCl}$, and then vigorously agitated the carriers with a glass rod to shed the biofilm off the carriers. The suspension was transferred into a $2000 \mathrm{~mL}$ volumetric flask. The agitating and shedding operations were repeated triplicate using $200 \mathrm{~mL}$ PBS. Almost all biofilm attached on the carrier surface was removed into the suspension. The suspension was all transferred into the volumetric flask and prepared $2000 \mathrm{~mL}$ sample with PBS for the following experiments. Four samples were taken from the four reactors for the total biomass by dry weight (DW) measurement of the biofilms and the adsorption amounts detection of the heavy metals in the biofilms.

On the 60th day of the experiment, i.e. on the October 20, 2015 , the four samples were taken from the four reactors for the DW measurement of the biofilms and the adsorption amounts detection of the heavy metals in biofilms again in a similar manner.

\section{Measurement of Total Biomass by DW of Biofilm}

The total biomass of biofilm was measured in terms of DW. After vigorous shaking, $50 \mathrm{~mL}$ homogeneous suspension sample was put into a crucible [10]. After weighed, the crucible was placed in a GZX-9140MBE electric blast drying oven (Boxun Industrial Co., Ltd., Shanghai) and dried at $105^{\circ} \mathrm{C}$, until constant weight was achieved. The crucible was then placed in a desiccator to cool to room temperature and weighed again. The DW of the biofilm sample was calculated in units of $\mathrm{g} \cdot \mathrm{kg}^{-1}$ of carrier and the measurement was repeated three times and the average was used as the final result. The biofilms samples were preserved in dry conditions and prepared for the following heavy metals detection.

\section{Extraction and Analysis of Extracellular Polymeric Substances (EPS)}

The EPS were extracted using a cation exchange resin (CER) extraction method according to Frolund et al. [11]. The yields of EPS are represented by polysaccharide (PS) and protein $(\mathrm{PN})$ which are the primary components of EPS in biofilm. CER (Tianjin Reagent Co. Ltd., China), at a dosage of $60 \mathrm{~g} \cdot \mathrm{g}^{-1}$ suspension solid, was added to the biofilm samples and mixed in a homogenizer for $1 \mathrm{~h}$ at $4^{\circ} \mathrm{C}$, allowing EPS in biofilm samples to be fully extracted. The residual solids were removed by a High-speed Refrigerated Centrifuge 5804R (Eppendorf, Germany) at 8,000 rpm for 15 min. The supernatant was used for PS and PN analysis. The PS and PN were determined by the phenol-sulfuric acid method and the Coomassie procedure, respectively [12,13]. The tests were in triplicate and took the averages as the final results with the units of $\mathrm{mg} \mathrm{EPS} \cdot \mathrm{g}^{-1}$ carrier.

\section{E. Sample Digestion}

The biofilms samples were treated by waterish digestion under common pressure [14]. Firstly, $0.2000 \mathrm{~g}$ of sample was added to $50-\mathrm{mL}$ beaker, where a small amount of water was put to wet the samples. Hereafter, $6 \mathrm{~mL}$ of hydrochloric acid and $2 \mathrm{~mL}$ of nitric acid were added to the samples separately; after $15 \mathrm{~min}$., the beakers were heated by electric heating panel until the residual solution was evaporated absolutely, then cooling down. After $3 \mathrm{~mL}$ of perchloric acid was put in high beakers, samples were heated until large amounts of thick white smoke vanished, hereafter cooling down. If the samples became dark, a small amount of perchloric acid (around $1 \mathrm{~mL}$ ) was put in the beakers repeatedly. Afterwards, $2 \mathrm{~mL}$ of nitric acid and $20 \mathrm{~mL}$ of ultrapure water were put in the beakers successively, then heating until the solid in the beakers was dissolved completely. Finally, water samples were filtered by microporous membrane $(0.45 \mu \mathrm{m})$, then making the volume constant. Each water sample had three repeats, and blank test was conducted at the same time.

\section{F. Sample Determination}

Using ICP-AES method, the contents of $\mathrm{Cu}, \mathrm{Pb}, \mathrm{Zn}, \mathrm{Cd}$, $\mathrm{Mn}$ and $\mathrm{Ni}$ in the biofilm samples were measured, respectively. Among the working parameters of ICP-AES instrument, the radio frequency (RF) power was $1.3 \mathrm{~kW}$; cooling gas flow, assistant gas flow and nebulizer gas flow were $15.0,0.2$ and $0.8 \mathrm{~L} / \mathrm{min}$, respectively; the observation mode was axial or radial, and the solution uptake rate was 15 $\mathrm{mL} / \mathrm{min}$. The working parameters of the ICP-AES instrument 
were shown in Table III. The analytical wavelengths of the determined heavy metal elements of $\mathrm{Cu}, \mathrm{Pb}, \mathrm{Zn}, \mathrm{Mn}, \mathrm{Ni}$ and Cd were 327.393, 220.353, 206.200, 228.180, 257.610 and $231.604 \mathrm{~nm}$, respectively (Table IV). The biofilms samples collected from the above were determined repeatedly, and the averages were taken.

TABLE III. OPERATING PARAMETERS OF OPTIMA 5300DV ICP-AES

\begin{tabular}{ll}
\hline ICP-AES working parameters & Setting value \\
\hline Radio Frequency $(\mathrm{RF})$ power $(\mathrm{KW})$ & 1.3 \\
Cooling gas flow $(\mathrm{L} / \mathrm{min})$ & 15 \\
Assistant gas flow $(\mathrm{L} / \mathrm{min})$ & 0.2 \\
Nebulizer gas flow $(\mathrm{L} / \mathrm{min})$ & 0.8 \\
Observation mode & Radial or axial \\
Solution uptake rate $(\mathrm{mL} / \mathrm{min})$ & 15 \\
\hline
\end{tabular}

TABLE IV. ANALYTICAL WAVE LENGTHS OF THE DETERMINED HEAVY MET AL ELEMENTS

\begin{tabular}{ccccccc}
\hline $\begin{array}{c}\text { Heavy metal } \\
\text { element } \\
\text { Analytical } \\
\text { wave length } \\
(\mathrm{nm})\end{array}$ & $\mathrm{Cu}$ & $\mathrm{Pb}$ & $\mathrm{Zn}$ & $\mathrm{Mn}$ & $\mathrm{Ni}$ & $\mathrm{Cd}$ \\
\hline
\end{tabular}

\section{RESULTS AND DISCUSSION}

\section{A. Characteristics of Biofilms}

The experiment tested the heavy metals adsorption capacities of the biofilms attached on the magnetic carriers and lasted for 60 days. After the carriers were put into the four reactors and the experiment operated about 3 days, thin layers of biofilm would be observed attaching onto the four kinds of carriers and there were no difference of the biofilms. On the 30th day, the biofilms attached on the four kinds of carriers showed significant differences in quantities. Concretely, the biofilms grown on $\mathrm{nMC}, \mathrm{MC} 01, \mathrm{MC} 02$, and MC03 gradually became deep in colors and increased in quantities, respectively. The change trend in quantities could be deductively observed from the column charts of total biomass by DW and total EPS production of the biofilms grown on the four kinds of carriers in the four reactors (Figure 2 and Figure 3).

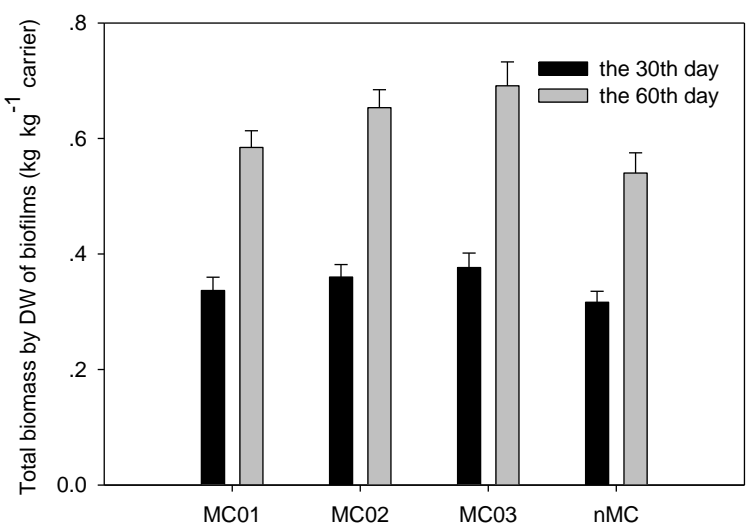

Figure 2. Total biomass by DW in biofilms attached on the magnetic and non-magnetic carriers.

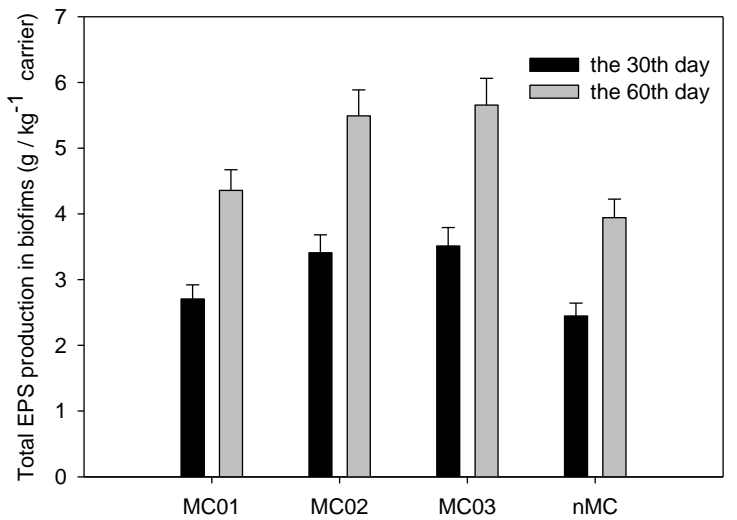

Figure 3. Total EPS production in biofilms grown on the magnetic and non-magnetic carriers.

\section{B. Heavy Metals Adsorption Capacities of Biofilms Grown on Maganetic Carriers}

The adsorption of biofilms to heavy metals has the potential advantage of high efficiency [1]. This study designed an experiment to test the adsorption capacities of 3 kinds of magnetic carriers and one kind of non-magnetic carriers. The adsorption capacities of the 4 kinds of carriers to the heavy metals, i.e. $\mathrm{Cu}, \mathrm{Pb}, \mathrm{Zn}, \mathrm{Cd}, \mathrm{Mn}$ and $\mathrm{Ni}$, were shown in figure 4 to figure 9 . There were two parts in every of the six figures: Part (a) showed the adsorption capacities with per gram dry biofilms, and Part (b) showed with per kilogram carriers. The six figures of Parts (a) showed the average or comprehensive adsorption capacities of all the living and nonliving organisms in the biofilms grown on the four kinds of carriers to the six kinds of heavy metals. The six figures of Parts (b) showed the direct or intuitive adsorption capacities of the four kinds of magnetic and nonmagnetic carriers.

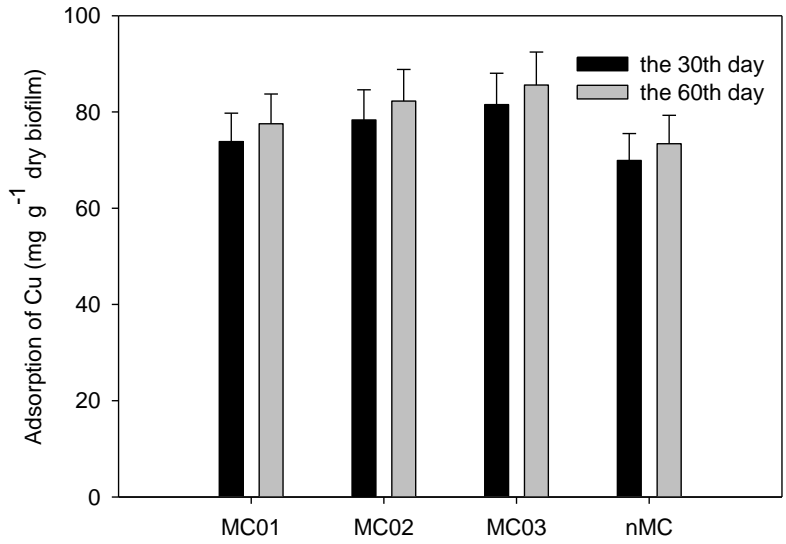

(a) 


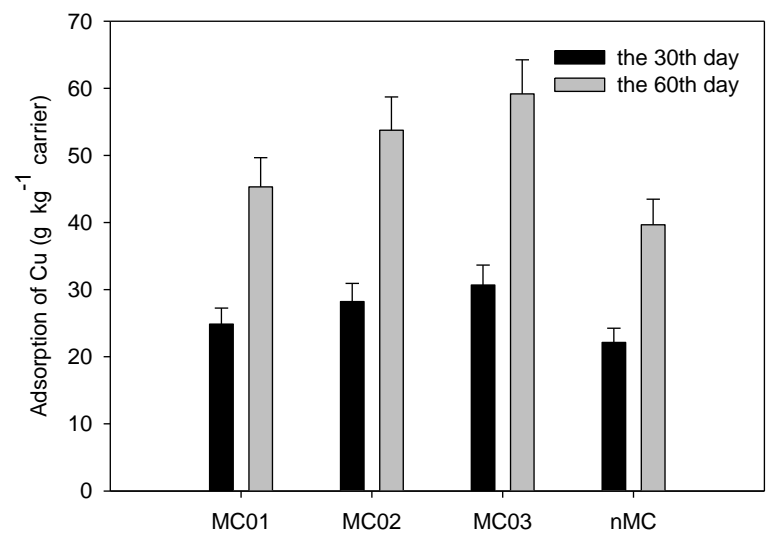

(b)

Figure 4. Adsorption capacities of heavy metal Cu.

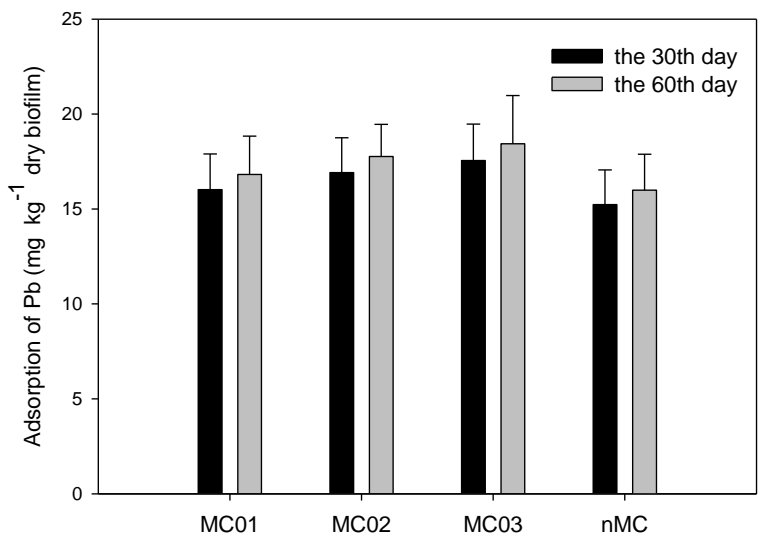

(a)

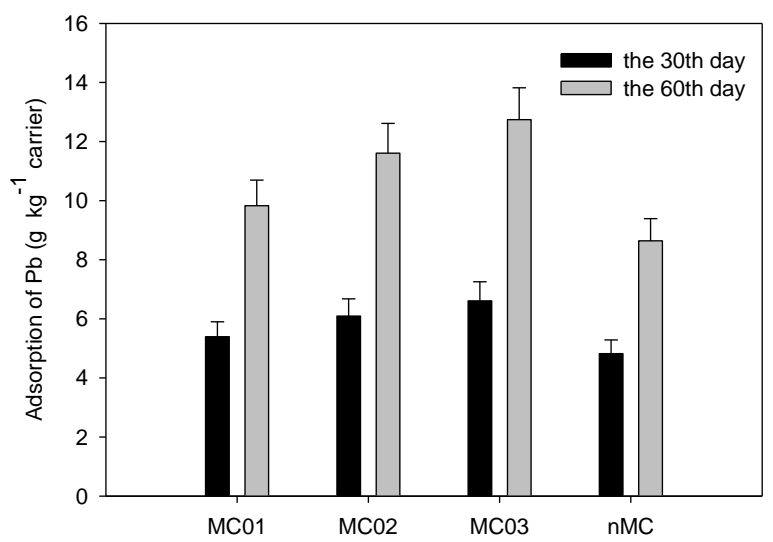

(b)

Figure 5. Adsorption capacities of heavy metal $\mathrm{Pb}$.

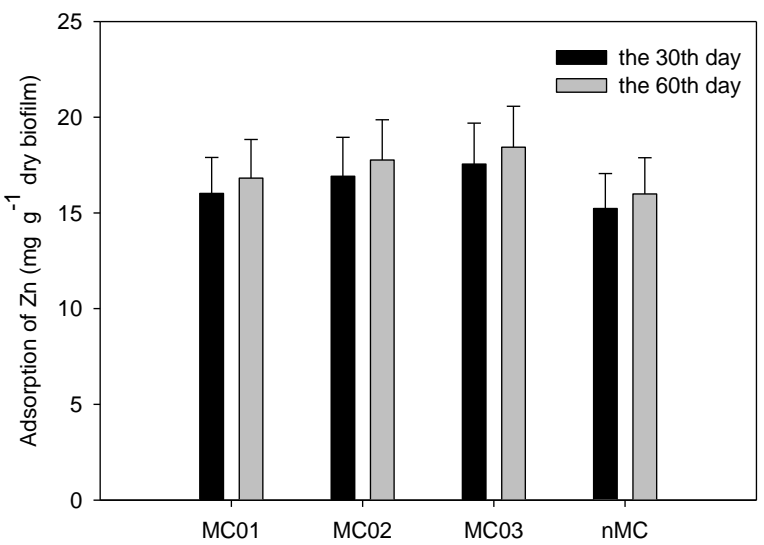

(a)

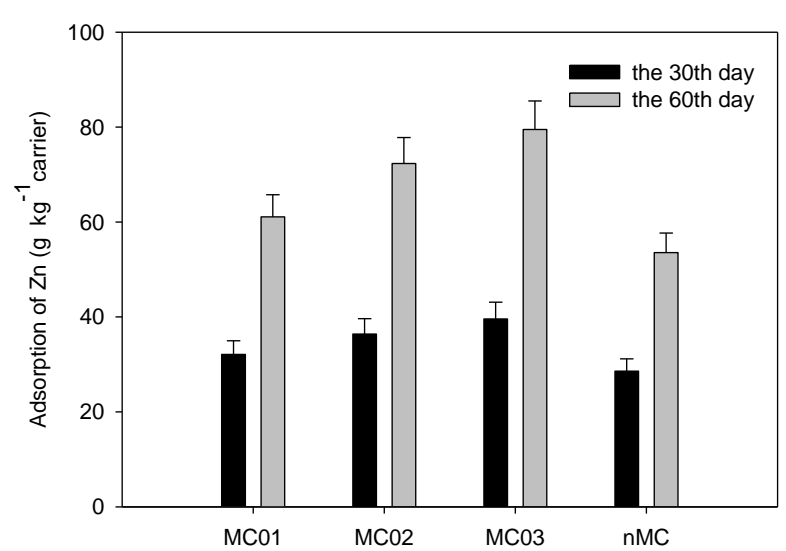

(b)

Figure 6. Adsorption capacities of heavy metal $\mathrm{Zn}$.

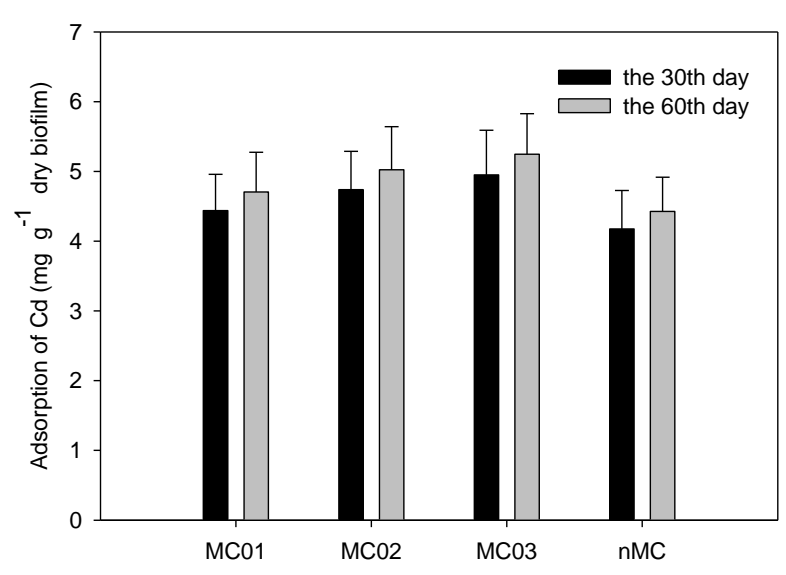

(a) 


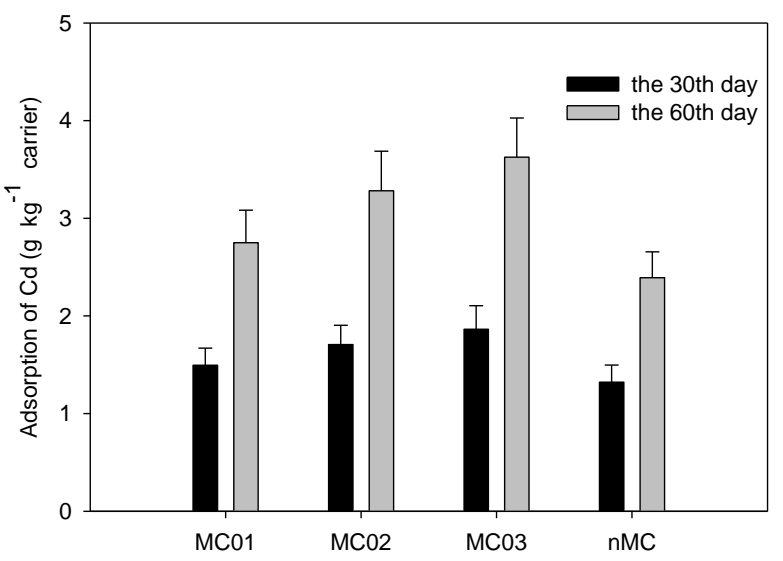

(b)

Figure 7. Adsorption capacities of heavy metal Cd.

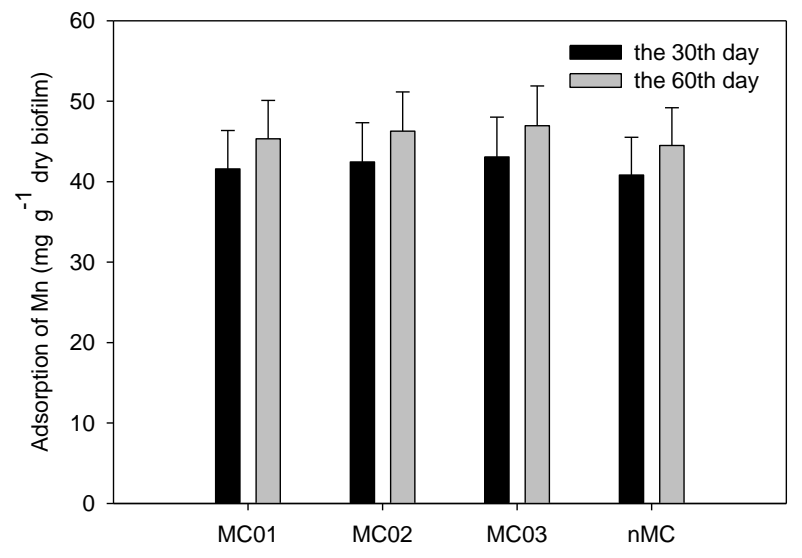

(a)

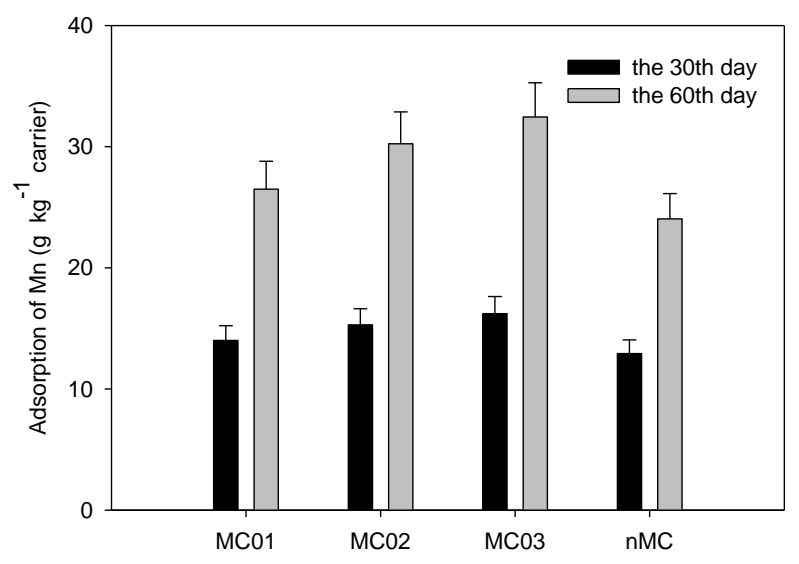

(b)

Figure 8. Adsorption capacities of heavy metal Mn.

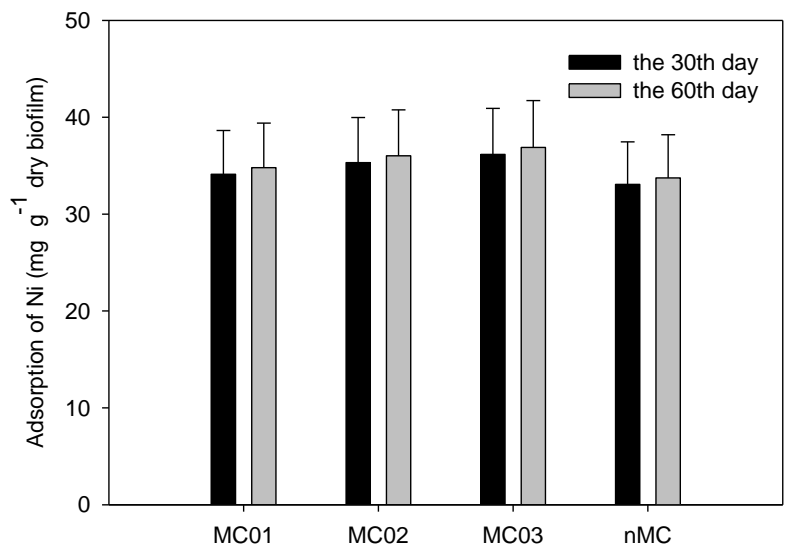

(a)

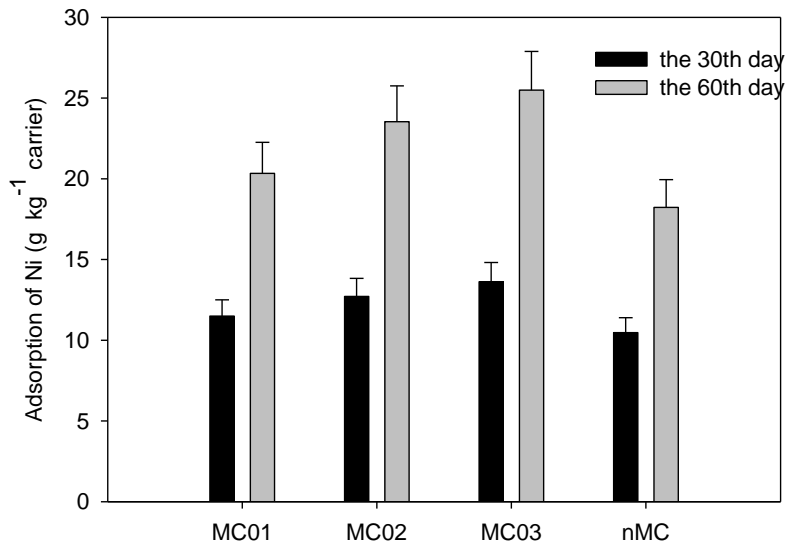

(b)

Figure 9. Adsorption capacities of heavy metal Ni.

As was obviously shown in figure 4 to figure 9 that the adsorption capacities of the magnetic carriers was more than that of the non-magnetic carriers to heavy metals, and increased with the magnetic field strength enhancing in MC01, MC02 and MC03, respectively. Taking the adsorption capacities of copper as an example (Figure 4), the adsorption amounts were 69.91, 72.84, 76.35 and $80.52 \mathrm{mg} \cdot \mathrm{g}^{-1}$ dry biofilm or 22.13, 24.54, 27.49 and $30.32 \mathrm{~g} \cdot \mathrm{kg}^{-1}$ carrier, and the adsorption amounts of MC01, MC02 and MC03 were approximately $4.19 \%, 9.21 \%$ and $15.18 \%$ per gram dry biofilm or $10.87 \%, 24.24 \%$ and $37.03 \%$ per kilogram carrier more than that of nMC on the 30th day, respectively, and the adsorption amounts of the four carriers to copper had the similar change trends on the 60th day. To the other heavy metals, the similar adsorption capacity change trends of the four carriers were also easily obtained from Figure 5 to Figure 9.

\section{Influence Factors of Heavy Metal Adsorption Capacities in Biofilms}

The biofilms formation under various environmental conditions showed a great difference in the adsorption to the 
heavy metals [15]. The adsorption capacity of heavy metals in biofilms was affected by many factors. The main influence factors such as the materials and characteristics of carriers, microbial species or groups in biolfilms, total EPS productions, categories and forms of heavy metals were listed and discussed as following.

\section{1) Materials and characteristics of carriers}

The materials and characteristics of carriers directly influence the formation rate and quantities of biofilms grown onto the substrata surface of the carriers. The hydrophilicity of the materials selected for making the carriers is one of the most properties which may determine the ease or difficulty level of the biofilm formation and the total biomass which are proportion to the adsorption amounts of heavy metals in biofilms over a period of time. Therefore, the high molecular materials containing hydrophilic groups such as hydroxyl, ester and carboxyl are often selected to make carriers. In this study, the component of PET which contained enormous amount of ester and having strong hydrophilic property were selected to make the carriers used in this experiment. The magnetic field is another important influence factor to the adsorption capacities of heavy metals in biofilms. The carriers named MC01, MC02 and MC03 contained 5\%, 10\% and $15 \%$ components of strontium ferrite powder, respectively. Before the three kinds of carriers were assembled in the reactor, they magnetized and had magnetic field strength with about $0.15,0.30$ and $0.40 \mathrm{mT}$ (Table I). The total biomass by DW of MC01, MC02 and MC03 were approximately $8 \%, 21 \%$ and $28 \%$ more than that of $\mathrm{nMC}$ on the 60th day, respectively (Figure 2). As can be explained by that the magnetic treatment which can change the physical and chemical properties of water such as the surface tension, the viscosity, the ionic speciation and solubility and the osmotic pressure promote the metabolism of organisms in biofilms, and thus the growth rate of biofilm is accelerated [6].

\section{2) Microbial species or groups in biolfilms}

There are many kinds of microbes in biofilms such as bacteria, fungi and algae. A certain kind of microbial species has different adsorption capacities to different kinds of heavy metals and the different microbial species have different adsorption capacities to a certain kind of heavy metal. For example, the adsorption capacities of the heavy metals $\mathrm{Zn}$ and $\mathrm{Pb}$ were 30.0 and $135.0 \mathrm{mg} \cdot \mathrm{g}^{-1}$ biosorbents of Streptomyces rimosus, and the adsorption capacities of the heavy metal $\mathrm{Cu}$ were 381 and $16.3 \mathrm{mg} \cdot \mathrm{g}^{-1}$ biosorbents of Bacillus firmus and Bacillus sp., respectively [16 19]. In this study, the adsorption capacities of biofilms showed as a comprehensive adsorption capacities of many species of microbes in biofilms, for example, the heavy metal $\mathrm{Cd}$ comprehensive adsorption capacities in biofilms of MC03 carriers showed as 43.07 and $46.95 \mathrm{mg} \cdot \mathrm{g}^{-1}$ dry biofilm on the 30th and 60th day, respectively (Figure 7).

3) Total EPS productions in biolfilms

The EPS were some viscous substances secreted by microbes can enhance the attachment of biofilms and facilitate their formation [20]. The components of EPS mainly include polysaccharides and protein, and in addition, they also contained a small amount of humus, humic acid and oil [21]. A large number of studies have indicated that the adsorption capacities of the biofilms to heavy metals is attributed to the total EPS production in biofilms [22]. The productions of EPS were closely related with magnetic field strength and increased with the enhancing of magnetism, as was observed obviously in Figure 3. Many studies showed that magnetic field promoted the metabolism and growth of the microorganisms in biofilms, and thus the biofilms in magnetic field manifested growing faster than that in nonmagnetic field [23].

\section{4) Categories and forms of heavy metals}

The categories and forms of heavy metals in water also significantly influence the adsorption capacities of heavy metals in biofilms. The adsorption of heavy metals in biofilms is selective in a certain degree, and is closely linked with the properties of heavy metals themselves. Allen and Brown suggested that the selective adsorption of microorganisms to various heavy metals was closely associated with the electronegativity, ion potential and ionic radius of metal ions, and oxidation-reduction potential [24]. Zheng et al. found that the selective adsorption capacity of biofilms to various heavy metals was consistent with that of single heavy metal, and the partition coefficient of each heavy metal went down greatly compared with that of single heavy metal when there existed many heavy metals [25]. It was because that total concentration of heavy metals showed increasing trend when many kinds of heavy metals coexisted, and the competition of the adsorption sites to heavy metals reduced their partition coefficient in biofilms. In addition, the migration and transformation of heavy metals are directly decided by their forms in water, and the dissolved heavy metals are exchanged and adsorbed easily from sediment onto the biofilms via water body, while non-dissolved heavy metals could be adsorbed or desorbed on the biofilms surface only through suspended particulates in water body.

5) Other influence factors

In a particular situation, temperature, $\mathrm{pH}$, sunlight, sources and nature of pollutants and hydrological conditions in tidal rivers might become the dominant factors influencing the adsorption capacities of heavy metals in biofilms. For instance, the hydrological conditions of the tidal rivers were the important factors influencing the adsorption capacities of heavy metals in biofilms [26]. For the tidal river, the frequency and intensity of tide fluctuation, geology, sediment properties and even the width of the river can affect the river water velocities and the concentrations of suspended matters in rivers, and so further influence the characteristics of the biofilms utilized to restore the river water, and at last influence the adsorption capacities of the heavy metals in biofilms.

\section{CONCLUSIONS}

This study designed an experiment to test the adsorption capacities of heavy metals in biofilms grown on the magnetic carriers. The results showed that the heavy metal adsorption capacities were more than that grown on the non-magnetic carriers, and that the adsorption capacities of heavy metals absorbed in biofilms grown on the magnetic carriers added 
with the increasing of the strontium ferrite powder components contained in the magnetic carriers, in which the magnetic field strength was proportion to the component of strontium ferrite powder contained in them after they were magnetized by use of a magnetizing machine. It was also showed that the adsorption amounts of heavy metals in biofilms were direct proportion to the total biomass by DW and total EPS production which was closely related to the component amounts of strontium ferrite powder.

There can be no doubt that the heavy metal adsorption capacities of the biofilms grown on the magnetic carriers had the potential advantage of high efficiency. It is a beneficial attempt to further study on how to utilize the magnetic carriers to practically restore the heavy metal polluted river water. The magnetic carriers can be widely used to ecologically remediate the water polluted by heavy metals.

\section{ACKNOWLEDGMENTS}

This work was supported by the Water Resources Science and Technology Innovation Project of Guangdong Province (Grant No. 2012-15 and No. 2014-12), the National Natural Science Foundation of China (Grant No. 51409287), and the Natural Science Foundation of Guangdong Province (Grant No. 2015A030313866).

\section{REFERENCES}

[1] J. L. Wang and C. Chen, Research advances in heavy metal removal by biosorption, Acta Sci. Circumst., 40 (4): 673-701 (2010).

[2] W. J. Tian, F. H. Hao and J. B. Zhai, Elasticity plastic filller for purification of polluted streams in situ entering lake, Environ. Sci., 29 (5): 1309-1312 (2008).

[3] C. C. M. Ip, X. D. Li, G. Zhang, C. S. C. Wong and W. L. Zhang, Heavy metal and $\mathrm{Pb}$ isotopic compositions of aquatic organisms in the Pearl River Estuary, South China, Environ. Pollut., 138 (3): 494-504 (2005).

[4] L. Strasak, V. Vetterl and L. Fojt, Effects of $50 \mathrm{~Hz}$ magnetic fields on the viability of different bacterial strains, Electromagn. Biol. Med., 24 (3): 293-300 (2005).

[5] R. L. Moore, Biological effects of magnetic fields: studies with microorganisms, Canad. J. Microbiol., 25: 1145-1151 (1999).

[6] J. G. Zhang and F. Y. Xu. Osmotic pressure and ion shape determination of magnetic treatment water, Chin. J. Phys. Medic. Rehabil. 17: 182 (1989).

[7] Y. Ji, Y. Wang, J. Sun, T. Yan, J. Li, T. T. Zhao, X. H. Yin and C. J. Sun, Enhancement of biological treatment of wastewater by magnetic field, Biores. Techn., 101 (22): 8535-8540 (2010).

[8] Z. X. Li, L. H. Yuan, H. Y. Lei, Y. J. Wang and H. L. Tang, Study on adsorption and migration regularity of heavy metals by biofilm in tidal rivers, J. Anhui Agric. Sci., 39 (34): 21217-21220 (2011).

[9] Y. P. Wang, Characteristics of water quality and heavy metals in Guangdong section of the Pearl River Basin, MS thesis, South China University of Technology (Guangzhou, China, 2012), pp. I.
[10] M. H. Christine and B.K. Douglas, The estimation of microbial biomass, Biosen., 1: 17-84 (1985).

[11] B. Frolund, R. Palmgren, K. Keiding and P.H. Nielsen, Extraction of extracellular polymers from activated sludge using a cation exchange resin, Water Res., 30: 1749-1758 (1996).

[12] M. Bradford, A rapid and sensitive method for the quantitation of microgram quantities of protein utilizing the principle of protein-dye binding, Anal. Biochem. 72: 248-254 (1976).

[13] P. Gerhardt, R. G. E. Murray, W. A. Wood and N. R. Krieg (Eds.), Methods for General and Molecular Bacteriology, American Society for Microbiology (Washington, DC, 1994).

[14] P. Y. Ancion, G. Lear, A. Dopheide and G. D. Lewis, Metal concentrations in stream biofilm and sediments and their potential to explain biofilm microbial community structure, Environ. Pollut., 173: 117-124 (2013).

[15] M. Horváth, G. Halász, E. Kucanová, B. Kuciková, I. Fekete, D. Remeteiová, G. Heltai and K. Flórián, Sequential extraction studies on aquatic sediment and biofilm samples for the assessment of heavy metal mobility, Microchem. J., 107 (SI): 121-125 (2013).

[16] N. Mameri, N. Boudries, L. Addour, D. Belhocine, H. Lounici, H. Grib, and A. Pauss, Batch zinc biosorption by a bacterial nonliving Streptomyces rimosus biomass, Wat. Research, 33 (6):1347-1354 (1999).

[17] A. Selatnia, A. Boukazoula and N. Kechid, Biosorption of lead (II) from aqueous solution by a bacterial dead Streptomyces rimosus biomass, Biochem. Eng. J., 19 (2):127-135 (2004c).

[18] H. Salehizadeh and S. A. Shojaosadati, Removal of metal ions from aqueous solution by polysaccharide produced from Bacillus firmus, Wat. Research, 37 (17):4231-4235 (2003)

[19] S. Tunali, A. Cabuk and T. Akar, Removal of lead and copper ions from aqueous solutions by bacterial strain isolated from soil, Chem. Eng. J., 115 (3):203-211 (2006).

[20] S. Wijeyekoon, T. Mino, H. Satoh and T. Matsuo, Growth and novel structural features of tubular biofilms produced under different hydrodynamic conditions, Wat. Sci. Technol., 41:129-138 (2000).

[21] P. X. Sheng, Y. P. Ting, J. P. Chen and L. Hong, Sorption of lead, copper, cadmium, zinc, and nickel by marine algal biomass: Characterization of biosorptive capacity and investigation of mechanisms, J. Colloid Interface Sci., 275 (1):131-141 (2004).

[22] Y. Liu, M. C. Lam and H. H. P. Fang, Adsorption of heavy metals by EPS of activated sludge, Water Sci. Technol., 43 (6): 59-66 (2001).

[23] L. O. Santos, R. M. Alegre, C. Garcia-Diego and J. Cuellar, Effects of magnetic fields on biomass and glutathione production by the yeast Saccharomyces cerevisiae, Process Biochem., 45 (8): 1362-1367 (2010).

[24] S.J. Allen and P.A. Brown, Isotherm analyses for single component and multi-component metal sorption onto lignite, J. Chem. Technol. Biotechnol., 62 (1):17-24 (1995).

[25] N. Zheng, X. Y. Hua, D. M. Dong and L. Ji, Competitive adsorption of metal cations onto natural surface coatings, J. Jilin University (Science Edition), 43 (3): 387-393 (2005).

[26] H. Sato, S. Yanai, N. Yu, A. Nagasaka and H. Sato, Influence of land use on suspended sediment discharge from watersheds emptying into Funka Bay, southwestern Hokkaido, northern Japan, J. Jpn. Soc. Hydrol. Water Resour., 15: 117-127 (2002).

[27] Ecological restoration. 